\title{
Choroidal neovascularization after intraocular foreign body
}

\section{Ester Fernández-López \\ Mari Carmen Desco- \\ Esteban \\ Adriana Fandiño-López \\ Mikhail Hernández-Díaz \\ Amparo Navea}

Department of Vitreoretinal Diseases, FISABIO Oftalmología Médica,

Valencia, Spain

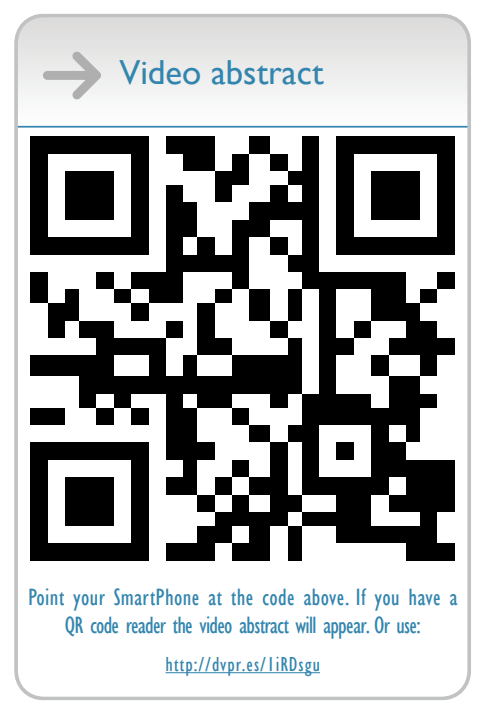

Correspondence: Ester Fernández-López Bifurcación Pío Baroja-General Aviles, S/N 460I 5 Valencia, Spain

Tel +34962328100

Email ester.fzlopez@gmail.com

This article was published in the following Dove Press journal:

Clinical Ophthalmology

16 May 2014

Number of times this article has been viewed

Abstract: We report an unusual case of choroidal neovascularization secondary to intraocular foreign body (IOFB) penetrating trauma. A 44-year-old man was referred to our department for IOFB trauma in the right eye. Vitrectomy and IOFB extraction was performed with good visual results. However, 2 months after surgery, he returned complaining of a drop in visual acuity. Choroidal neovascularization originating from a direct choroidal rupture at the IOFB impact site was observed. The patient was treated with 6-monthly intravitreal injections of antivascular endothelial growth factor, and showed regression of neovascularization and a final visual acuity of $20 / 80$. IOFB trauma is a serious condition, indeed in spite of initially good results after a favorable surgical outcome. Choroidal neovascularization after direct traumatic choroidal rupture is usually aggressive and requires more active antivascular endothelial growth factor therapy.

Keywords: choroidal rupture, choroidal neovascularization, intravitreal, antivascular endothelial growth factor, intraocular foreign body, open globe injury

\section{Introduction}

Choroidal neovascularization (CNV) secondary to traumatic choroidal rupture is a rare condition normally related to indirect choroidal rupture following nonpenetrating closed globe blunt trauma. Between $10 \%$ and $20 \%$ of indirect choroidal ruptures are associated with CNV., Rupture of Bruch's membrane, the inflammatory process, and the consequent abnormal production of proangiogenic mediators explain its pathogenesis. ${ }^{3}$ It has been reported to appear between 1 month and up to 4 years after ocular trauma. ${ }^{1,2}$ However, very few papers document the outcome of direct damage to the choroid following intraocular foreign body (IOFB) trauma in an open globe injury, ${ }^{4-6}$ and the most frequent complication in these cases is development of proliferative vitreoretinopathy leading to complex retinal detachment. The purpose of this paper is to describe an unusual case of post-traumatic CNV secondary to direct choroidal rupture as the result of a metallic IOFB, with emphasis on the antivascular endothelial growth factor (VEGF) dosing regimen.

\section{Case report}

A 44-year-old man was referred to our department for IOFB trauma in the right eye caused by a penetrating trauma with a metallic airgun pellet. Best corrected visual acuity was hand motion in his right eye. Slit-lamp biomicroscopy showed a $2 \mathrm{~mm}$ self-sealed corneal perforation and a white cataract. Fundus examination revealed vitreous hemorrhage and the retina could not be visualized. The IOFB was confirmed by computed tomography. We proceeded to cataract removal, 23-gauge pars plana vitrectomy, and extraction of the $3 \mathrm{~mm}$ metallic IOFB with forceps through a corneal incision. A primary intraocular lens was implanted in the ciliary sulcus. Peripheral 
endophotocoagulation at the impact site of the IOFB and fluid-air exchange completed the surgery. A juxtafoveolar superior nasal contusion of the IOFB with choroidal rupture was visualized during the procedure, and demonstrated by spectral-domain optical coherence tomography.

Best corrected visual acuity improved to 20/50, but 2 months later the patient complained of blurred vision and metamorphopsia. Ophthalmoscopic examination revealed a juxtafoveolar retinal hemorrhage surrounded by white-yellowish retinal edema and perifoveal retinal striae radiating from the retinal impact site. Optical coherence tomography and fluorescence angiography demonstrated a juxtafoveal type $2 \mathrm{CNV}$ originating from the edge of the choroidal rupture (Figure 1). After obtaining informed consent from the patient, an off-label intravitreal injection of bevacizumab $(0.05 \mathrm{~mL}, 1.25 \mathrm{mg})$ was administered once a month for 4 consecutive months. One month after the fourth injection, regression of the CNV was identified, but best corrected visual acuity remained 20/100 due to subretinal scar tissue. Three months later, the patient returned with a recurrence of CNV activity and increased central macular thickness (Figure 2). Two additional bevacizumab injections were administered, achieving a final reduction in subretinal fluid and central macular thickness (Figure 3). Best corrected visual acuity improved to 20/80, with no recurrence after 2 years of follow-up.

\section{Discussion}

Penetrating trauma with IOFB impact into the retina is a serious condition with a poor visual prognosis. The most frequent complication in these cases is postoperative proliferative vitreoretinopathy, with proliferation of fibrous membranes due to communication between subretinal tissues (choroid, sclera) and the inner ocular cavity, leading to recurrent secondary retinal detachment. ${ }^{7}$ Nevertheless, other "minor" complications can worsen the visual prognosis after successful reconstructive surgery. CNV after IOFB trauma, as occurred in our patient, is one of the rare complications.

CNV following IOFB trauma may be promoted by several factors. Choroidal rupture after trauma initiates a tissue remodeling process at the injury site, which includes an inflammatory and angiogenic response with fibrovascular proliferation. ${ }^{3}$ Higher levels of VEGF have been related to penetrating ocular trauma and IOFB trauma by other authors, ${ }^{8}$ and can trigger $\mathrm{CNV}$ in these cases.

Anti-VEGF therapy has been shown to be useful in a few reported cases ${ }^{1,9,10}$ of indirect traumatic CNV following blunt trauma, with good visual and anatomic recovery, often after

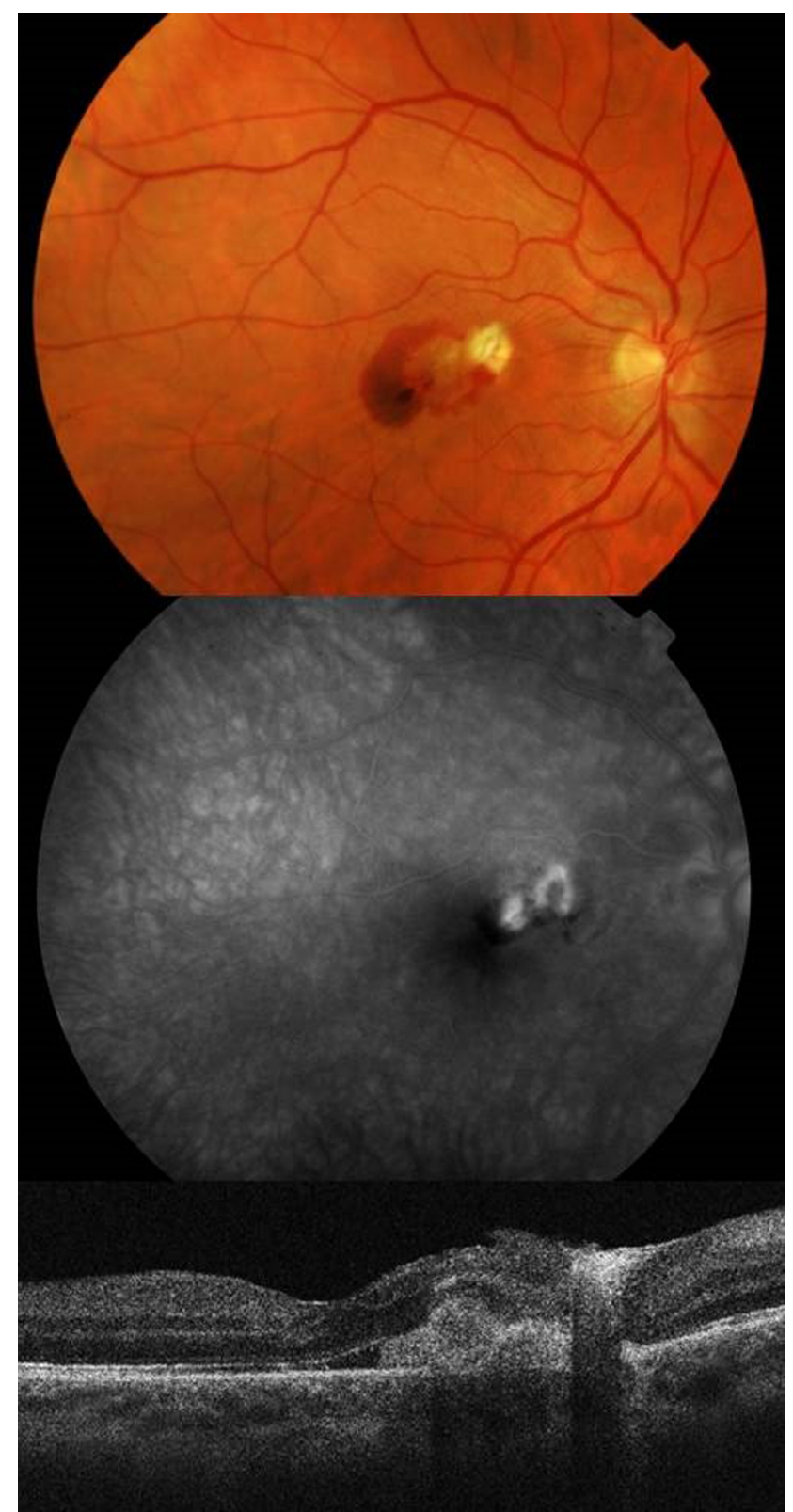

Figure I Juxtafoveolar subretinal choroidal neovascularization with subretinal fluid adjacent to the choroidal rupture 2 months after vitrectomy demonstrated by optical coherence tomography and fluorescein angiography.

a single injection. However, to the authors' knowledge, there is only one reported case in the PubMed database describing the outcome of CNV secondary to IOFB direct choroidal rupture treated with bevacizumab. ${ }^{4}$ This case required three consecutive intravitreal injections to achieve regression of $\mathrm{CNV}$ and had a final best corrected visual acuity of 20/200. In our case, six intravitreal injections of bevacizumab were required to inactivate $\mathrm{CNV}$, with a final best corrected visual acuity of 20/80.

Among the prognostic factors associated with poor visual outcomes in $\mathrm{CNV}$ after traumatic choroidal rupture, ${ }^{2}$ rupture 


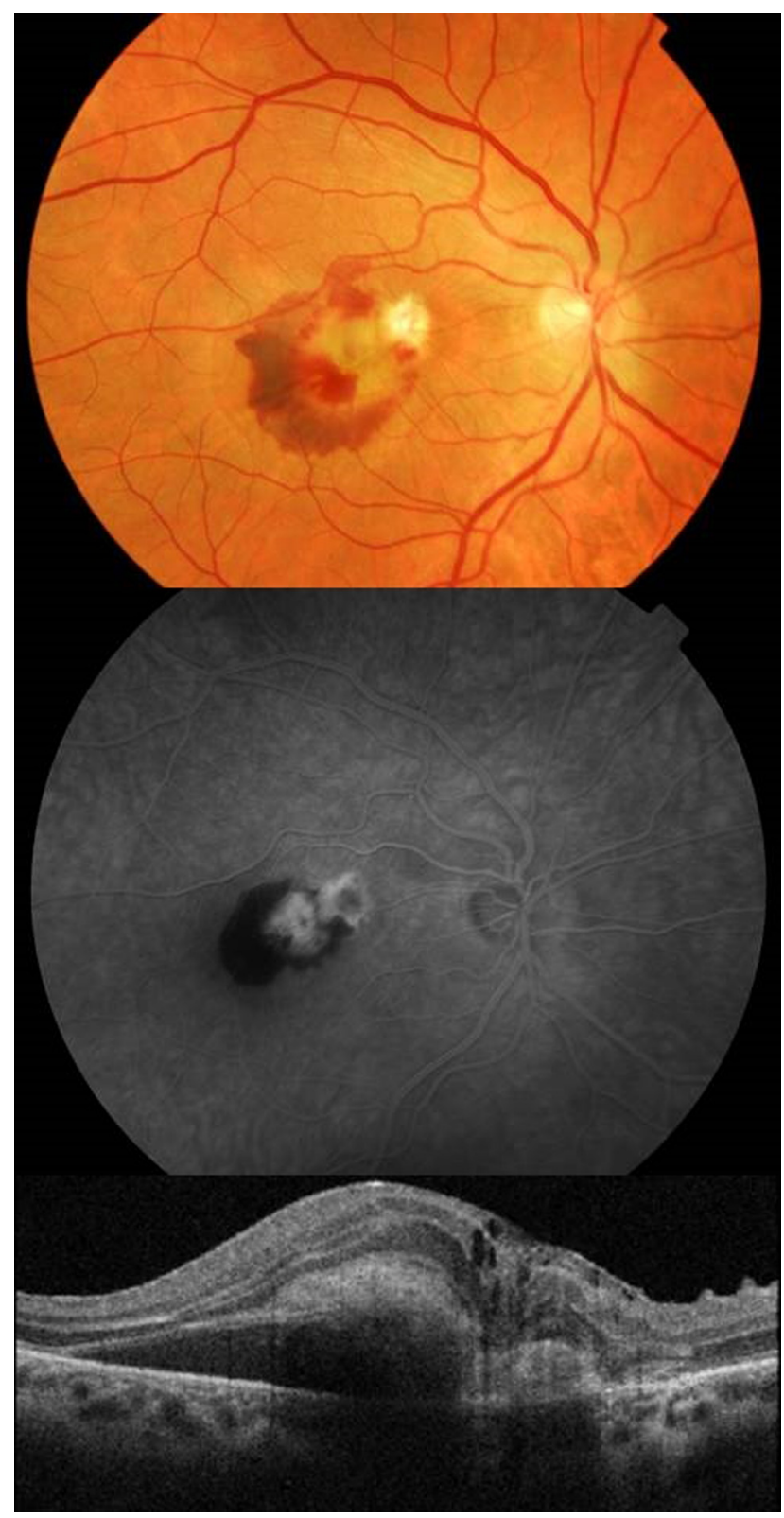

Figure 2 Recurrence of the choroidal neovascularization activity with a centra macular thickness of $349 \mu \mathrm{m}$.

close to the center of the fovea is one of the main ones and was present in our patient. Most patients do not achieve a final visual acuity better than 20/40 in this situation. Moreover, direct choroidal ruptures secondary to IOFB trauma may lead to more aggressive $\mathrm{CNV}$ than indirect ruptures, probably due to greater activation of proangiogenic and inflammatory mediators with a direct impact on the retina and causing extensive damage to the subretinal tissues.

On the other hand, considering that this was a vitrectomized eye, the half-life of intravitreal anti-VEGF was probably shorter than normal, so requiring more frequent injections.

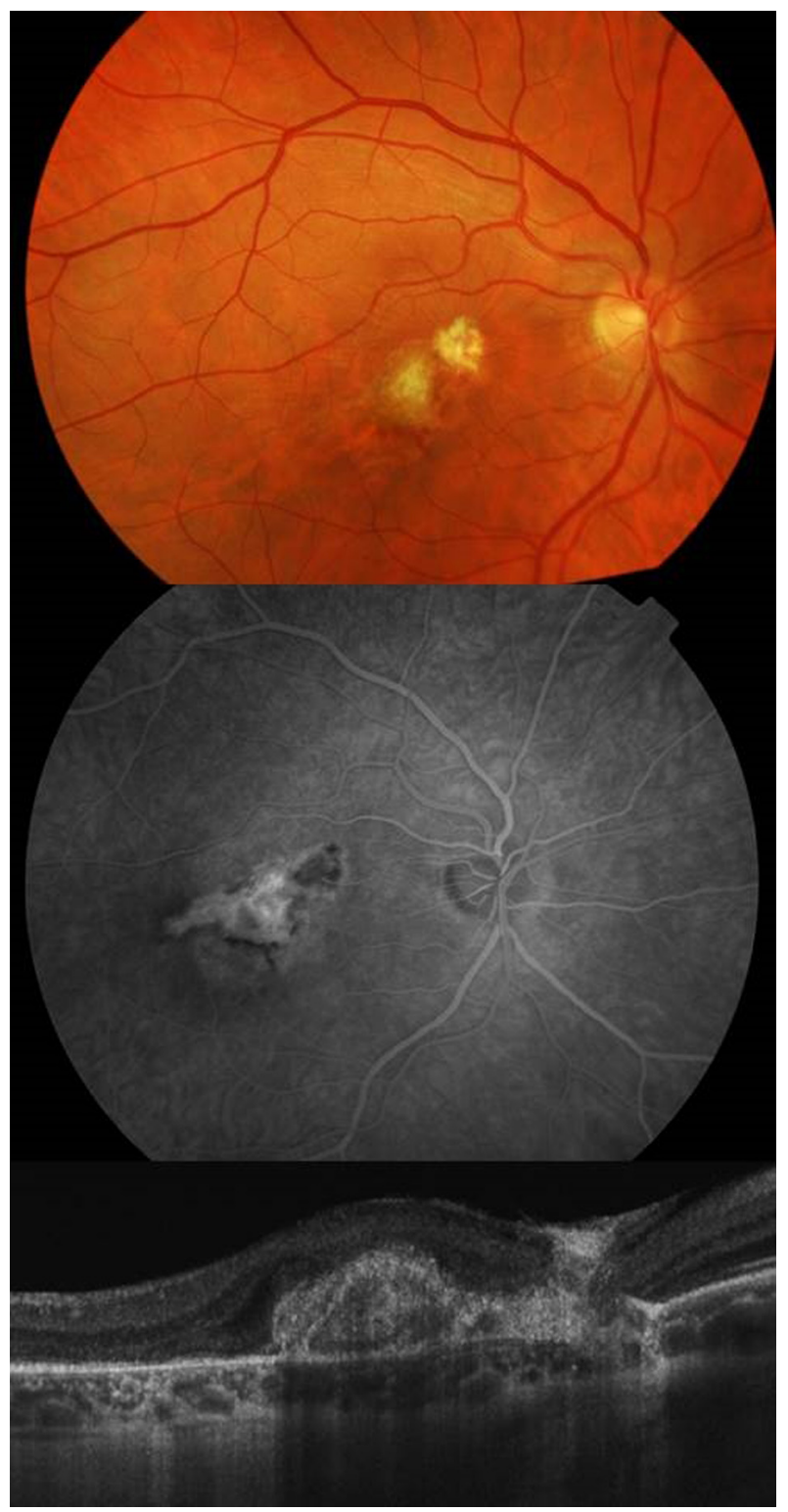

Figure 3 Spectral-domain optical coherence tomography confirmed reduction of the choroidal neovascularization activity with a central macular thickness of $275 \mu \mathrm{m}$ and disappearance of the retinal hemorrhage. Leakage from the choroidal neovascularization in the fluorescein angiography had ceased.

Therefore, in view of this report, it seems that direct choroidal rupture after IOFB trauma may lead to more aggressive CNV, requiring a higher anti-VEGF dosing regimen from the outset. The more rapid clearance of intravitreal drugs should also be considered when planning intravitreal injections in these patients, regarding they are vitrectomized.

Further investigations are needed to establish the best dosing regimen in these patients and whether we should consider earlier intravitreal injection of anti-VEGF at the time of primary surgical repair to decrease the degree of fibrovascular proliferation during the healing process. 


\section{Disclosure}

The authors report no conflicts of interest in this work.

\section{References}

1. Valldeperas X, Bonilla R, Romano MR, de la Cámara J. [Use of intravitreal bevacizumab for the treatment of choroidal neovascularization secondary to choroidal rupture]. Arch Soc Esp Ophthalmol. 2011;86:380383. Spanish.

2. Ament CS, Zacks DN, Lane AM, et al. Predictors of visual outcome and choroidal neovascular membrane formation after traumatic choroidal rupture. Arch Ophthalmol. 2006;124:957-966.

3. Kent D, Sheridan C. Choroidal neovascularization: a wound healing perspective. Mol Vis. 2003;22:747-755.

4. Chen TL, Sun MH, Lin KK, Lai CC, Chen KJ. Intravitreal bevacizumab with regression of subretinal neovascularization after intraocular foreign body trauma. $J$ Trauma. 2010;68:747.

5. Trimble SN, Schatz H. Subretinal neovascularization following metallic intraocular foreign-body trauma. Arch Ophthalmol. 1986;104:515-519.
6. Nego B, Turut P, Malthieu D, Sellam R, Krzykala B. [New sub-retinal vessel after chorio-retinal wound caused by intraocular foreign body (1 case)]. Bull Soc Ophthalmol Fr. 1989;89:263-265. French.

7. Cardillo JA, Stout JT, LaBree L, et al. Post-traumatic proliferative vitreoretinopathy. The epidemiologic profile, onset, risk factors, and visual outcome. Ophthalmology. 1997;104:1166-1173.

8. Merlak M, Kovacević D, Balog T, et al. Vascular endothelial growth factor in aqueous humor of patients with perforative eye injuries. Coll Antropol. 2008;32:33-37.

9. Artunay O, Raseier R, Yuzbasioglu E, Sengül A, Bahcecioglu H. Intravitreal bevacizumab injection in patients with choroidal neovascularization due to choroidal rupture after blunt-head trauma. Int Ophthalmol. 2009;29:289-291.

10. De Benedetto U, Battaglia M, Knutsson KA, et al. Intravitreal bevacizumab for extrafoveal choroidal neovascularization after ocular trauma. J Ocul Pharmacol Ther. 2012;28:550-552.
Clinical Ophthalmology

\section{Publish your work in this journal}

Clinical Ophthalmology is an international, peer-reviewed journal covering all subspecialties within ophthalmology. Key topics include: Optometry; Visual science; Pharmacology and drug therapy in eye diseases; Basic Sciences; Primary and Secondary eye care; Patient Safety and Quality of Care Improvements. This journal is indexed on

Submit your manuscript here: http://www.dovepress.com/clinical-ophthalmology-journal

\section{Dovepress}

PubMed Central and CAS, and is the official journal of The Society of Clinical Ophthalmology (SCO). The manuscript management system is completely online and includes a very quick and fair peer-review system, which is all easy to use. Visit http://www.dovepress.com/ testimonials.php to read real quotes from published authors. 